\title{
On the case...
}

\section{Diabetic gastroparesis}

in pre pregnancy

\section{By Erin M. Jones, MSN, WHNP, and Kathryn Evans Kreider, DNP, FNP, BC-ADM, FAANP}

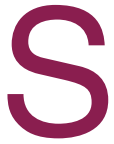

B, a 25-year-old Black female with type 1 diabetes presents to the emergency department with complaints of nausea, vomiting, and blood glucose levels upward of $285 \mathrm{mg} / \mathrm{dL}$. A pregnancy test at this visit is positive, with an ultrasound providing an estimated gestational age of 10 weeks.

\section{Health history}

SB tells the healthcare provider she sees in the emergency department she was diagnosed with type 1 diabetes mellitus at the age of 12 years after experiencing excessive bouts of thirst. She discloses a lengthy history of difficulty controlling her diabetes. She was unable to manage an insulin pump due to its complexity and also thought it made her look unattractive. Additionally, she often has trouble remembering to administer her subcutaneous injections when she is busy socializing with her friends. Furthermore, SB reports three hospital admissions for diabetic ketoacidosis (DKA) within the past year. She also reports more frequent urinary tract infections, increased fatigue, loss of appetite, as well as worsening peripheral neuropathies and retinopathy.

She tells the provider that she decided to come to the emergency department today because she has

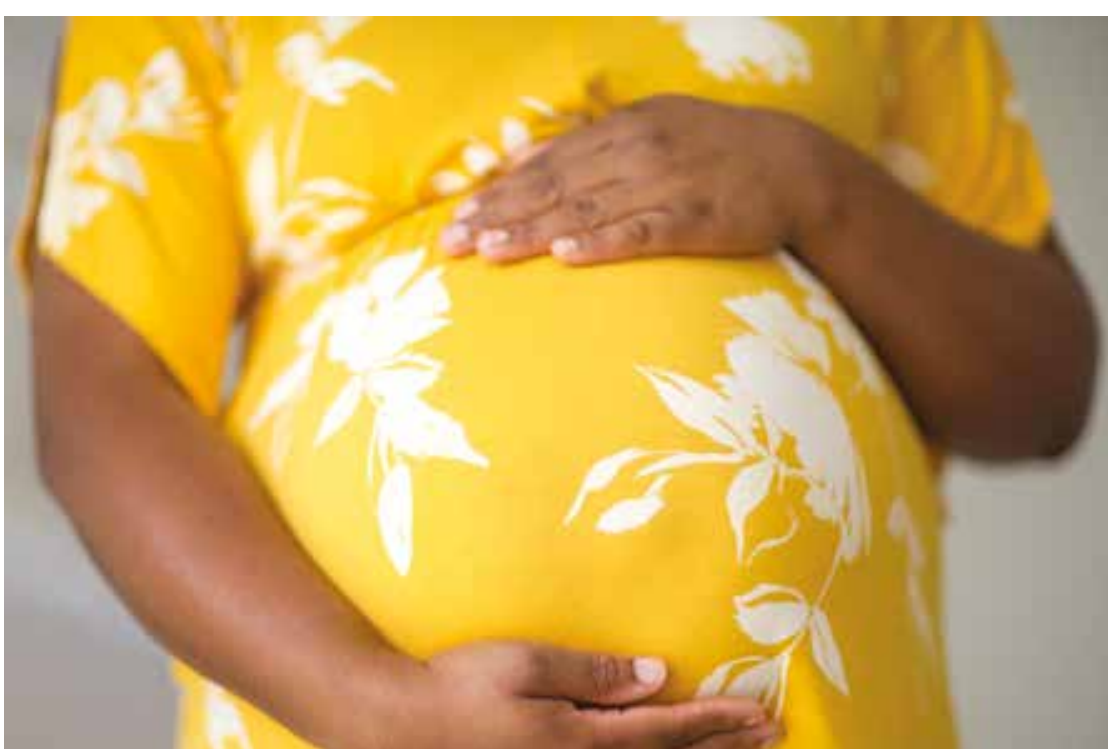

not been able to tolerate food or fluids for the last few weeks and that the nausea and vomiting she has been experiencing is getting worse. She has also started having some abdominal pain that she rates as $8 / 10$. She says she suspected she might be pregnant and is worried because she has been losing weight. This is a first pregnancy for SB.

\section{Physical examination}

SB's vital signs are stable. Her weight is $95 \mathrm{lbs}$ and body mass index is 17.9. Based on her report that she weighed about $118 \mathrm{lbs}$ prior to her nausea and vomiting, this is a significant loss of $23 \mathrm{lbs}$ over the past few weeks. Lab results reveal a hemoglobin $\mathrm{A} 1 \mathrm{c}$ of $10.6 \%$. Her point-of-care blood glucose reading of $285 \mathrm{mg} / \mathrm{dL}$ and an anion gap of 20 indicates DKA.

\section{Initial diagnosis}

SB is admitted to the hospital with a diagnosis of hyperemesis gravidarum (HG) complicated by type 1 diabetes. A multidisciplinary team from maternal fetal medicine, nutrition, gastroenterology, psychiatry, and general surgery is assembled to collaborate in her care.

\section{Hyperemesis gravidarum}

Nausea and vomiting of pregnancy 
Table 1. Hyperemesis gravidarum and diabetic gastroparesis comparison ${ }^{1,3}$

\begin{tabular}{l|l|l}
\hline Timing & Hyperemesis gravidarum & Diabetic gastroparesis \\
\hline Signs and symptoms & Primarily first trimester; may persist & Related to diabetes; exacerbated in pregnancy \\
\hline Complications & Persistent vomiting with nausea, weight loss & $\begin{array}{l}\text { Nausea, vomiting, abdominal pain, early satiety, } \\
\text { postprandial fullness, bloating, weight loss }\end{array}$ \\
\hline Diagnosis & $\begin{array}{l}\text { Orthostatic hypotension, electrolyte imbalance, } \\
\text { hypovolemia, Wernicke encephalopathy, } \\
\text { esophageal rupture }\end{array}$ & $\begin{array}{l}\text { Severe dehydration, malnutrition } \\
\text { Stepwise treatment }\end{array}$ \\
$\begin{array}{l}\text { Hypokalemia, increased hematocrit, increased } \\
\text { BUN \& urine-specific gravity, elevated } \\
\text { liver enzymes, transient hyperthyroidism, } \\
\text { hypomagnesemia and hypocalcemia }\end{array}$ & $\begin{array}{l}\text { Upper endoscopy, computed tomography, and/ } \\
\text { or magnetic resonance imaging to rule out other } \\
\text { gastrointestinal disorders } \\
\text { Scintigraphy showing delayed gastric emptying }\end{array}$ \\
\hline $\begin{array}{l}\text { Dietary modification } \\
\text { Hydration } \\
\text { Doxylamine-pyridoxine } \\
\text { Diphenhydramine or meclizine } \\
\text { Add dopamine antagonist } \\
\text { Ondansetron } \\
\text { Glucocorticoids for refractory cases }\end{array}$ & $\begin{array}{l}\text { Dietary modification } \\
\text { Optimize glycemic control } \\
\text { Hydration } \\
\text { Metoclopramide } \\
\text { Erythromycin } \\
\text { Diphenhydramine } \\
\text { Ondansetron } \\
\text { Prochlorperazine } \\
\text { Invasive intervention }\end{array}$ \\
\hline
\end{tabular}

BUN, blood urea nitrogen.

are common conditions that often manifest early in pregnancy. Although $\mathrm{HG}$ does not have a single definition, it is often a diagnosis of exclusion. ${ }^{1}$ The American College of Obstetricians and Gynecologists (ACOG) asserts that the most common findings are persistent vomiting unrelated to other causes, weight loss, and acute starvation. ${ }^{1}$ If a patient experiences nausea and vomiting for the first time after 9 weeks of gestation, other conditions must be considered as HG typically manifests before this time. ${ }^{1}$

\section{Diabetic gastroparesis}

Distinguishing diabetic gastroparesis from HG in a pregnant patient with diabetes mellitus can be difficult, especially if the patient has no reported history of gastroparesis prior to pregnancy. Diabetic gastroparesis has been referred to as a neuropathy occurring within the gastrointestinal system. ${ }^{2}$ Defining symptoms of diabetic gastroparesis are nausea, vomiting, anorexia, weight loss, abdominal pain, and postprandial fullness, all of which may be seen in HG. ${ }^{2}$ However, delayed gastric emptying and gastric outlet obstruction provide a more intense sensation of bloating that is often not found in patients with $\mathrm{HG}^{3}{ }^{3}$ When differentiating $\mathrm{HG}$ and diabetic gastroparesis, it is important to note that although mild epigastric pain after vomiting is expected, persistent upper abdominal pain or fullness is not a characteristic of HG (Table 1). ${ }^{1,3}$

\section{Management during initial hospitalization}

Management during the initial hospitalization for SB includes correcting DKA through fluid replacement, insulin, and electrolyte control.

Once glucose control is achieved, a stepwise approach is taken to tackle the nausea and vomiting of HG. The use of vitamin B6 and doxylamine is unsuccessful, so antiemetics and promotility agents are introduced. ${ }^{1,3}$ Although the initial diagnosis was $H G$, a diagnosis of diabetic gastroparesis is added when the patient persists to have severe abdominal pain despite the stepwise approach for HG. In the setting of diabetic gastroparesis, dietary modification of a low-fat and low-fiber diet is often suggested, but due to SB's inability to tolerate oral intake this step is bypassed. Ultimately, the patient is prescribed a daily regimen of metoclopramide, ondansetron, famotidine, diphenhydramine, chlorpromazine, erythromycin, and dicyclomine to manage her nausea, vomiting, and abdominal pain and to promote gastric motility. Maternal fetal medicine, gastroenterology, endocrinology, and nutrition specialists work cohesively to develop appropriate regimens, and the patient is discharged home with a plan for extensive outpatient follow-up with each service.

\section{Management during pregnancy}

SB presented for admission to the obstetric service multiple times throughout the pregnancy with 
Table 2. Pregnancy timeline

\begin{tabular}{|c|c|c|c|c|c|c|c|}
\hline $\begin{array}{l}\text { Gestational } \\
\text { age }\end{array}$ & 10 weeks & 13 weeks & 15 weeks & $\begin{array}{l}17 \text { weeks-27 } \\
\text { weeks }\end{array}$ & 29 weeks & 31 weeks & 32 weeks \\
\hline $\begin{array}{l}\text { Reason for } \\
\text { admission }\end{array}$ & $\begin{array}{l}\text { Admitted for } \\
\text { DKA, n/v x } 1 \\
\text { week }\end{array}$ & $\begin{array}{l}\text { Admitted for } \\
\mathrm{n} / \mathrm{v}, \mathrm{HG} \text {, and } \\
\text { hyperglycemia } \\
\text { x } 1 \text { week }\end{array}$ & $\begin{array}{l}\text { Admitted for } \\
8 \text { days with } \\
\text { ketosis, n/v, HG }\end{array}$ & $\begin{array}{l}\text { Admitted for } \\
\text { DKA, HG, } \\
\text { persistent n/v }\end{array}$ & $\begin{array}{l}\mathrm{J} \text { tube } \\
\text { dislodged; } \\
\text { admitted } \mathrm{x} \\
3 \text { days and } \\
\text { replaced }\end{array}$ & $\begin{array}{l}\mathrm{J} \text { tube clogged; } \\
\text { admitted for } \\
\text { maintenance } \mathrm{x} \\
4 \text { days }\end{array}$ & $\begin{array}{l}\text { Admitted } \\
\text { for } n / \mathrm{v} \text {, } \\
\text { hyperglycemia, } \\
\text { fatigue, } \\
\text { new-onset } \\
\text { hypertension }\end{array}$ \\
\hline Treatments & \multicolumn{3}{|c|}{$\begin{array}{l}\text { IV hydration } \\
\text { Metoclopramide } \\
\text { Ondansetron }\end{array}$} & $\begin{array}{l}\text { PICC line } \\
\text { and TPN } \\
\text { started at } 18 \\
\text { weeks } \\
\text { J tube } \\
\text { placement } \\
\text { at } 23 \text { weeks }\end{array}$ & IV hydration & IV hydration & $\begin{array}{l}\text { Delivered at } \\
33 \text { weeks } 2 \\
\text { days }\end{array}$ \\
\hline
\end{tabular}

DKA, diabetic ketoacidosis; HG, hyperemesis gravidarum; IV, intravenous; n/v, nausea/vomiting; PICC, peripherally inserted central catheter; TPN, total parenteral nutrition.

starvation ketosis and persistent abdominal pain accompanied by nausea and vomiting. Intensified gastroparesis led to excessive weight loss and inability to tolerate oral intake as well as worsening glycemic control.

Although the previously prescribed medications alleviated some symptoms, she was still unable to tolerate oral fluids or solids. Additionally, as the pregnancy progressed, the increasing abdominal pressure worsened the gastroparesis. On the patient's fourth and longest admission, a nasogastric tube (NGT) placement was attempted, but SB was not able to tolerate it. The decision was made to start total parenteral nutrition (TPN), requiring placement of a peripherally inserted central catheter at 18 weeks of gestation. Long-term use of TPN is not without its risks including possible bloodstream infections and multiple metabolic complications. After 32 days of TPN and considering its longterm complications, the team decided to pursue a jejunostomy feeding tube to bypass the stomach completely. At 23 weeks of pregnancy, the patient underwent a laparoscopic insertion of a jejunostomy tube.
Throughout SB's hospitalizations, her blood glucose was monitored via hourly fingersticks. Daily electrocardiograms were done as the patient was receiving several potentially QT-prolonging medications. Daily weights were obtained as well as CMP [comprehensive metabolic panel] lab values each morning. Given the fluctuations in blood glucose between 45 and $280 \mathrm{mg} / \mathrm{dL}$, SB's insulin regimen was constantly adjusted. When managing an insulin regimen for patients with type 1 diabetes, the American Diabetes Association recommends calculating a total daily dose (TDD) of insulin based on a patient's weight with dosing ranging between 0.4 and 1.0 units $/ \mathrm{kg} /$ day. ${ }^{4}$ Once calculated, half of the insulin is meant to be given as basal and the other half is to be dispersed among meals. Both pregnancy and diabetic gastroparesis can affect insulin requirements. ${ }^{3,5}$ Severe gastroparesis with malnutrition often decreases basal dosing to 0.15 units $/ \mathrm{kg} /$ day, and caution as well as clinical judgment must be used in regard to bolus insulin. ${ }^{2}$

Because of her inability to tolerate meals, the patient's insulin regimen was structured differently than usual with the entirety of SB's TDD devoted toward a basal rate that was further adjusted to maintain target fasting values between $95 \mathrm{mg} / \mathrm{dL}$ and $105 \mathrm{mg} / \mathrm{dL}$. In lieu of mealtime dosing of insulin, the patient was placed on a correction scale that was calculated using an insulin sensitivity factor (ISF) of 1,700/TDD. A fingerstick was performed every 1 to 2 hours, and values above $220 \mathrm{~g} / \mathrm{dL}$ warranted correction with rapid-acting insulin. ACOG also recommends 2-hour postprandial glucose values to be less than $120 \mathrm{mg} / \mathrm{dL} .{ }^{6}$ Although this patient was rarely eating, the correction scale was formulated around achieving this value. If a blood glucose was taken and the value was below $220 \mathrm{mg} / \mathrm{dL}$, then no additional insulin was required.

\section{Pregnancy outcomes}

Over the course of her 33-week pregnancy, SB was admitted to the hospital on seven separate occasions for approximately a cumulative 17 weeks. Table 2 outlines the timeline, reasons for admission, and treatment provided. Admissions revolved 


\begin{tabular}{l|l}
$\begin{array}{l}\text { Interpregnancy } \\
\text { management/ annual } \\
\text { comprehensive diabetes } \\
\text { medical evaluation }\end{array}$ & $\begin{array}{l}\text { - Conduct comprehensive physical exam including fundoscopic exam and thorough foot exam } \\
\text { - Monitor lab values: lipid profile, liver function test, urinary albumin-to-creatinine ratio, serum } \\
\text { creatinine \& eGFR, TSH } \\
\text { - Encourage glycemic control } \\
\text { - Assess need for and provide contraception }\end{array}$ \\
\hline Preconception education & $\begin{array}{l}\text { - Counsel on possible maternal and fetal complications; preeclampsia, fetal anomalies, preterm delivery, } \\
\text { worsening diabetic retinopathy and nephropathy } \\
\text { - Encourage A1c } 6.0 \% \\
\text { - Start folic acid at } 800 \mu \text { daily }\end{array}$ \\
\hline Preconception assessment & $\begin{array}{l}\text { - Evaluate baseline complications: hypertension, nephropathy, retinopathy, cardiovascular disease } \\
\text { - Obtain 24-hour urine protein and creatinine } \\
\text { - Refer for ocular assessment by qualified eye care professional } \\
\text { - Consider screening studies for coronary artery disease if has multiple vascular risk factors } \\
\text { - Obtain TSH }\end{array}$ \\
\hline Postpartum education and & $\begin{array}{l}\text { - Educate about change in insulin requirements } \\
\text { - Assess need for and provide contraception } \\
\text { - Support breastfeeding; may lower insulin requirement further }\end{array}$
\end{tabular}

eGFR, estimated glomerular filtration rate; TSH, thyroid-stimulating hormone.

around management of nausea and vomiting, abdominal pain, weight loss, and malnutrition. SB developed preeclampsia with severe features at 33 weeks of pregnancy and received steroids for fetal lung maturation and was started on magnesium sulfate for eclampsia prophylaxis. Delivery was performed via cesarean section due to persistent preeclampsia and contraindication of vaginal delivery due to the jejunostomy tube. A female infant was delivered with Apgar scores of 7 and 8 at 1 and 5 minutes. The jejunostomy tube was discontinued on postpartum day 4 as SB began to tolerate food. Glycemic control was established, and SB was discharged on postoperative day 5 , while the baby spent 3 weeks in the neonatal intensive care unit. SB experienced complete resolution of nausea, vomiting, and abdominal pain.

Care provided by a multidisciplinary team was crucial for the positive pregnancy outcomes for SB and her infant. Obstetric care with maternal fetal medicine specialists was the primary service with significant gastroenterology and nutrition service collaboration.

\section{Postpartum and beyond}

Insulin requirements reduce dramatically in the immediate postpartum state and return to prepregnancy levels by 1 to 2 weeks postpartum. ${ }^{6,7}$ Therefore, the patient must be appropriately educated that the insulin dosing will be significantly less. ${ }^{5}$ Options related to family planning should be discussed prior to delivery so the patient may have the option of long-acting reversible contraception (LARC) placement at the time of delivery. Reliable contraception is crucial for this patient as avoiding unintended pregnancy is necessary. Although there is no robust literature to support it, many providers consider diabetic gastroparesis to be a contraindication to pregnancy. ${ }^{8}$ Due to the severity of SB's case, she was advised that she should not get pregnant again in the future, as the maternal and fetal risk is too high. Follow-up with the maternal fetal medicine specialist at both 2 weeks and 6 weeks was advised as well as visits with endocrinology and gastroenterology specialists at approximately 6 to 8 weeks postpartum. Screening for postpartum thyroiditis through measurement of TSH at both 3 and 6 months is recommended for patients with type 1 diabetes. ${ }^{9}$ Emphasis on adequate glycemic control and appropriate follow-up with specialists are imperative with SB. As pregnancy unveiled gastroparesis, it is also known to exacerbate retinopathy and nephropathy. ${ }^{6,10} \mathrm{SB}$ will need an assessment to determine if any other potential microvascular and macrovascular damage occurred as a result of the pregnancy (Table 3). 5,6,9,11

\section{Implications for women's health nurse practitioner practice}

Although there was no nurse practitioner present on the multidisciplinary team for this patient, utilization of a women's health nurse practitioner (WHNP) would have been appropriate. The educational competencies of the degree prepares WHNPs to participate in the care of high-risk antepartum and postpartum patients alike. The National Association of Nurse Practitioners in Women's Health WHNP guidelines for practice and education indicate that a WHNP is pre- 
pared to assess and diagnose highrisk pregnancies. ${ }^{12}$ Furthermore, a WHNP may participate in the management of high-risk pregnancies when collaborating with other multidisciplinary providers. Additionally, WHNP's knowledge of primary care provides a competency to assess, diagnose, and manage women with attention to nongynecologic health conditions such as diabetes and its impact on reproductive health. ${ }^{12}$ -

Erin M. Jones is a women's health nurse practitioner and Kathryn Evans Kreider is Associate Professor at Duke University School of Nursing in Durham, North Carolina. The authors have no actual or potential conflict of interest in relation to the contents of this article.

\section{References}

1. Committee on Practice Bulletins-Obstetrics. ACOG Practice Bulletin No. 189. Nausea and vomiting of pregnancy. Obstet Gynecol. 2018;131(1):e15-e30.

2. Krishnasamy S, Abell TL. Diabetic gastroparesis: principles and current trends in management. Diabetes Ther. 2018;9(suppl 1):1-42.

3. Bharucha AE, Kudva YC, Prichard DO. Diabetic gastroparesis. Endocr Rev. 2019;40(5):1318-1352.

4. American Diabetes Association. Glycemic targets: standards of medical care in diabetes-2020. Diabetes Care. 2020;43(suppl 1):S66-S76

5. American Diabetes Association. Management of diabetes in pregnancy: standards of medical care in diabetes-2020. Diabetes Care. 2020;43(suppl 1):S183-S192.

6. American College of Obstetricians and Gynecologists Committee on Practice Bulletins-Obstetrics. ACOG Practice Bulletin No. 201: Pregestational diabetes mellitus. Obstet Gynecol. 2018;132(6):e228-e248.

7. Sugrue R, Zera C. Pregestational diabetes in pregnancy.
Obstet Gynecol Clin North Am. 2018;45(2):315-331.

8. Hawthorne G. Maternal complications in diabetic pregnancy. Best Pract Res Clin Obstet Gynaecol. 2011;25(1):77-90.

9. Blumer I, Hadar E, Hadden DR, et al. Diabetes and pregnancy: an Endocrine Society clinical practice guideline. J Clin Endocrinol Metab. 2013;98(11):4227-4249.

10. Moore TR, Mouzon SH-D, Catalano P. Diabetes in pregnancy. In Creasy and Resnik's Maternal-Fetal Medicine: Principles and Practice, 8th ed. Elsevier; 2018.

11. American Diabetes Association. Microvascular complications and foot care: standards of medical care in diabetes-2020. Diabetes Care. 2020;43(suppl 1):S135-S151

12. National Association of Nurse Practitioners in Women's Health. Women's Health Nurse Practitioner: Guidelines for Practice and Education, 8th ed. Washington, DC: NPWH; 2020.

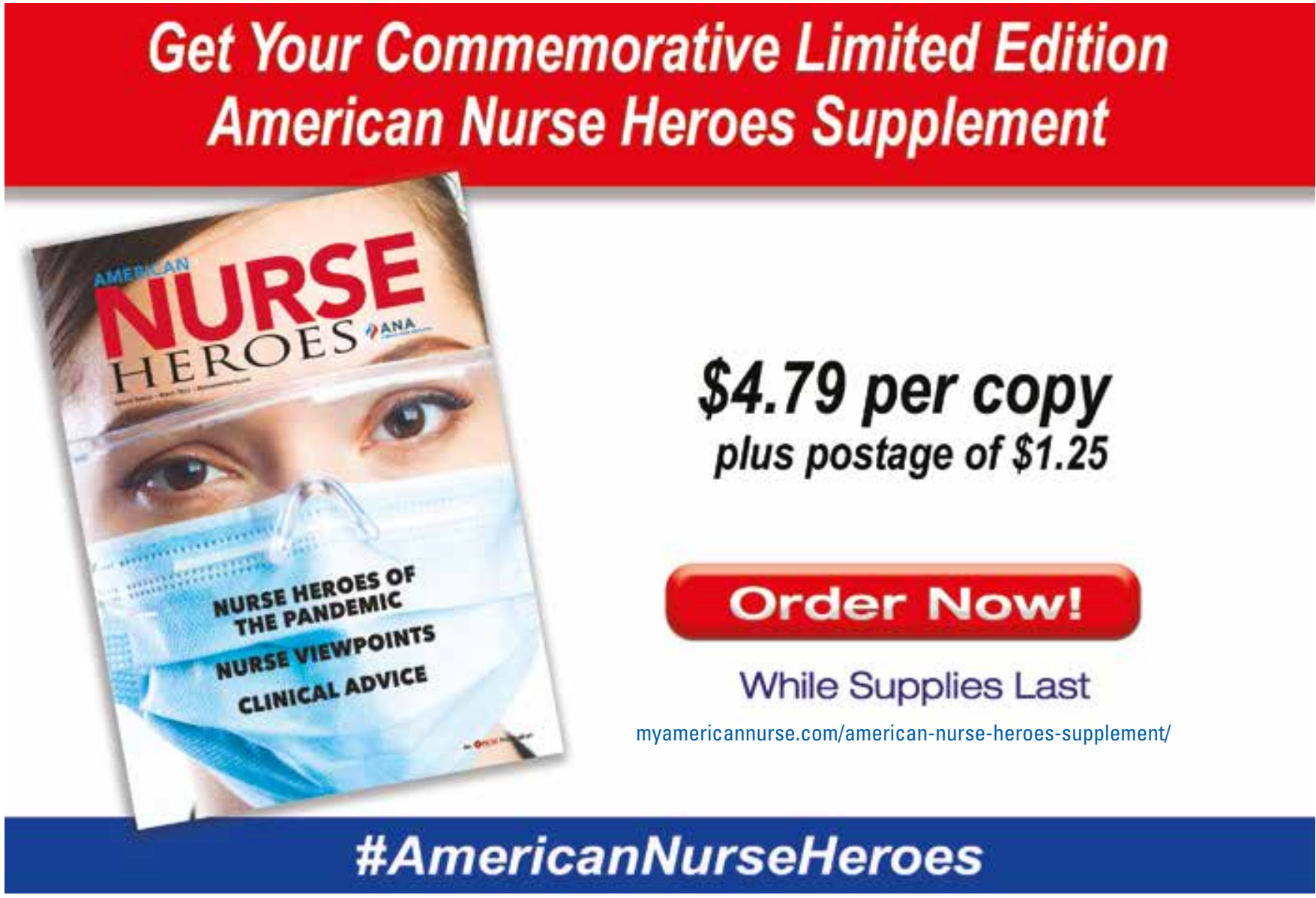

